\title{
Review on Inverter for Solar Applications and Power Quality Improvement
}

\author{
Prashant Samariya, Parmeshwar Kumawat
}

\begin{abstract}
In this busy world of limited sources solar energy is the unlimited power. Solar energy is the perpetual energy which a mankind should take advantage. To do this MPPT (Maximum Power Point Tracking) is the way to get this power and utilize it. MPPT is the algorithm which is used to extract maximum power from solar PV panels. There are different types of MPPT algorithms available to do this job, but $P \& O$ (perturbation and observation) is the easiest and sophisticated MPPT method to track maximum power. Voltage sags and swells, flickers, interruptions, harmonic distortion and many other distortion are the main problems of the power quality and these power quality problem which are arise due to a fault so to solve this, custom power devices are used.
\end{abstract}

Index Terms - Solar PV, MPPT, P\&O, Inverter, PWM, Power Quality.

\section{INTRODUCTION}

Electrical energy is the simple and well regulated form of energy, can be easily changed to other forms. Along with its quality and continuity has to maintain for good economy. Power quality has become main concern for today's power productions and users. Due to the increasing demand of electronic equipments, Power quality problems are arised by increasing demand of equipments.[1] Many disturbances related with electrical power are voltage sag, voltage swell, voltage flicker and harmonic contents. This reduces the efficiency and shortens the life time of end consumer equipment. There is also data and memory loss problems of electronic equipment like computer.

The main power quality problems are voltage sags/swells because of the complex structure of power system network which affects end users and industries and result in high losses. Voltage sag is a small period reduction in rms voltage which can be produced by a short circuit, overload and fault in the system and voltage swell, which is a momentary increase in voltage ,happens when a heavy load turns off in a power system.[2] The continuity of power supply can be maintained by clearing the faults at faster rate. To enhance the power quality the power quality problems i.e. voltage sag/swell, voltage harmonics flickering has to be compensated.

Prashant Samariya, Diploma Student, Vivekananda Global University, Jaipur (Rajasthan) INDIA.

Parmeshwar Kumawat, Assistant Professor and HOD, Department of Electrical Engineering, Vivekananda Global University, Jaipur (Rajasthan) INDIA.
The solar energy is the tremendous source of energy and that energy can be utilized to generate electrical energy. This is done by solar photovoltaic panel.

Nowadays solar panel has grown more use in generating electricity with free Fuel I.E, 'Sun'. Though there are some losses occur at the time of conversion and extraction and thus PV panels still stands important. We have limited conventional sources of energy which we are using readily, which will end one day but to preserve that for the future generations.

We should have to find another alternatives to these sources and thus solar is the future of power generation.

The solar energy plays an important role in various sectors for developing many green energy systems. The lack of fossil fuels gave rise to the generation of solar power generation. Hence the optional sources of energy has become more important in power generation because of their ample availability and Eco-friendly nature. The great advantage of solar power generation is that, it is pollution free, requires less maintenance. The power generated from solar energy can be used instead of generating power from coal or nuclear energy saving tremendous amount of cost and money.

The photovoltaic panel generates under different weather, irradiation and atmospheric conditions. So, sometimes it is not possible to get the maximum output from the panels and thus the efficiency of power generation reduces. MPPT allows to extract maximum power from the solar panels. To get maximum power through the variable temperature and irradiation conditions MPPT plays an important role.

\section{POWER QUALITY}

Most of international standards describe power quality as the electric supply secured from any changes in voltage, current or frequency under normal situations \& do not interrupt the customer's processes. Quality of power supply is mostly described by its two main factors : voltage quality \& supply reliability. These main factors cause power quality difficulties when they suffer deviation in their features due to failure of equipments or sudden disturbances in the system.[3]

The growing tendency of non linear loads cause harmful effects in the power system network suffered by the customer. Then the era of Custom Power devices introduced and eliminated these harmful effects caused by non linear loads. 


\section{MAXIMUM POWER POINT TRACKING}

Maximum power point tracking (MPPT) is the algorithm which is used with the electrical converters to track maximum power from the solar PV modules.

To improve the efficiency of the solar panels MPPT plays an important role. MPPT technique is generally used with PV solar system and wind turbines to maximize the extraction of power under various atmospheric and weather conditions. The transfer efficiency of power from solar cell is dependent upon the intensity of sun light falling on the panel and electric characteristics of load. With the variance of amount of sun light, the change in the load characteristics leads to the change in highest power transfer efficiency with system optimization.

This characteristics is called the maximum power point and the process of tracking this point and keeping the load characteristics there is called MAXIMUM POWER POINT TRACKING (MPPT). MPPT devices are commonly integrated into electrical power converter system that controls voltage or current conversion, regulation for driving various loads, filtering, batteries or motors, including power grids.

The power from MPP (Pmpp) is the product of MPP voltage and MPP current. The MPPT measures the voltage and current from the PV system and calibrates them to maintain the maximum power. There are different methods available for MPPT and some of them are widely used.

\section{MPPT TECHNIQUES}

The solar panel converts solar energy into electrical energy. The PV power generation has TWO main problems:

\section{A. Low conversion efficiency of electric power \\ B. High cost of PV cell}

As generation of power from the PV system completely depends upon the weather condition, so under low irradiation condition the efficiency is $9-16 \%$. The V-I characteristics of the solar cell is non-linear as it changes with the variation in irradiation, temperature and load impedance, where irradiation and temperature are dynamic. Due to this the location of maximum power point keeps changing continuously and unknown, but it can be located by search algorithms or by calculation models. Thus, the maximum power point tracking or MPPT techniques are basically used to maintain the operating point of the PV arrays at the Maximum power point. There are many different MPPT techniques available and used. One of them are widely used by the researchers as follow :-

1) Curve-Fitting Technique: MPP is the peak value of the PV panel's PV Characteristics, hence at first the PV panel's PV characteristic's is predicted in this technique. For the prediction of this PV characteristic, the PV panel modeling is done offline based on mathematical equation or numerical approximation.

To achieve an accurate P-V curve fitting, 3rd order polynomial function as

$\mathrm{P}=\mathrm{a} V^{3}+\mathrm{b} V^{2}+\mathrm{cV}+\mathrm{d}$

Where, the coefficient of a, b, c and d are determined by sampling of PV voltage and power in intervals. Differentiate of above equation gives,

$\mathrm{dP} / \mathrm{dV}=3 \mathrm{a} V^{2}+2 \mathrm{bV}+\mathrm{c}$

At MPP, $\mathrm{dP} / \mathrm{dV}=$ 0

2) Fractional Short Circuit Current (FSCI) Technique: There exists a single operating point called MPP at which the panel power is maximum at given condition of environment. If any one of MPP parameters i.e. voltage or current tracked by some way, then the corresponding MPP power can be tracked. in this techniques, depending on changes of environmental conditions and degradation level of PV panels, the nonlinearity of PV systems VI characteristics is modeled using mathematical expression. A mathematical relation between MPP current (Impp) and short circuit current (Isc) show's that Impp is linearly dependent on Isc. Impp $=\mathrm{Ksc} *$ Isc Where, Ksc varies between 0.64 and 0.85 .

3) Fractional Open Circuit Voltage (FOCV) Technique: In FOCV technique, MPP voltage (Vmpp) can calculated from the empirical relationship are as follows - Vmpp = Koc*Voc

Where, the value of Koc varies between 0.78 and 0.92. Koc may be calculated by analyzing the PV system at wide range of Irradiations and temperature.

In this method the Vmpp is calculated by open circuiting the PV system at load end for a fraction of seconds and Voc is measured.

1) Hybrid MPPT (HMPPT) Techniques: It is found that the $\mathrm{P} \& \mathrm{O}$ technique is the most extensively used is commercial MPPT system because it's very straight forward, accurate and easy to implement. Is accuracy and tracking time depend on the perturbation size. Hence, hybrid control techniques are essential. In a recent proposed HMPPT techniques with both $\mathrm{P} \& \mathrm{O}$ and ANN, the perturbation steps is continuously approximated by using ANN. it is accurate and fast. Using this $\mathrm{P} \& \mathrm{O}$ and ANN HMPPT on-line maximum power point tracking (MPP) is possible. It is advantageous, it doesn't depend on atmospheric conditions.

2) Perturb and Observe Technique: The $\mathrm{P} \& \mathrm{O}$ algorithms operate by periodically perturbing (i.e. increasing or decreasing) voltage or current of array terminal and comparing the PV output power with that of the previous perturbation cycle. If the operating voltage of PV array changes and power increases, the control system moves the PV array operating point in that direction if not then the operating point is 
moved in the opposite direction. In the next perturbation cycle the algorithm continues in the same as before. A common problem in $\mathrm{P}$ and $\mathrm{O}$ algorithms is that the terminal voltage of array is perturbed every MPPT cycle, therefore when the MPP is reached, the output power oscillates around the maximum result in power loss in the PV array system. This is especially true in constant or not quickly varying atmospheric conditions. Furthermore, P\&O methods can fail under rapidly changing atmospheric conditions (see below Fig.) Starting from an operating point A, if atmospheric conditions stay approximately constant, a perturbation $\Delta \mathrm{V}$ the voltage $\mathrm{V}$ will bring the operating point to $\mathrm{B}$ and the perturbation will be reversed due to a decrease in power. However, if the irradiance increases and shifts the power curve from $P_{1}$ to $P_{2}$ within one sampling period, the operating point will move from $\mathrm{A}$ to $\mathrm{C}$. This represents an increase in power and the perturbation is kept the same. Consequently, the operating point diverges from the MPP and will keep diverging if the irradiance steadily increases.

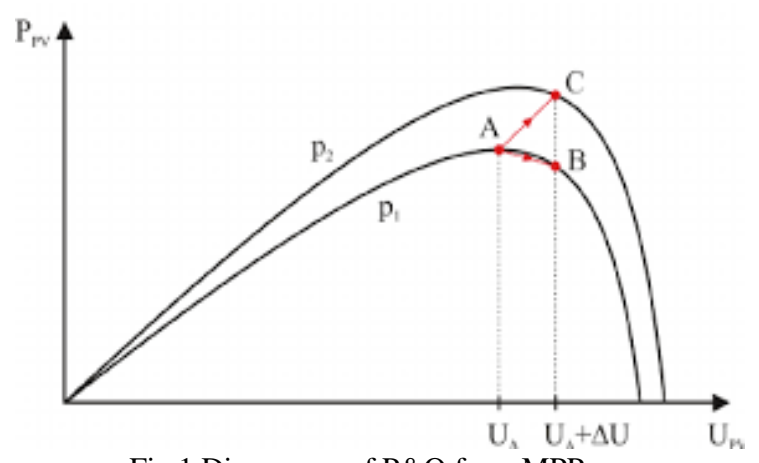

Fig.1 Divergence of P\&O from MPP

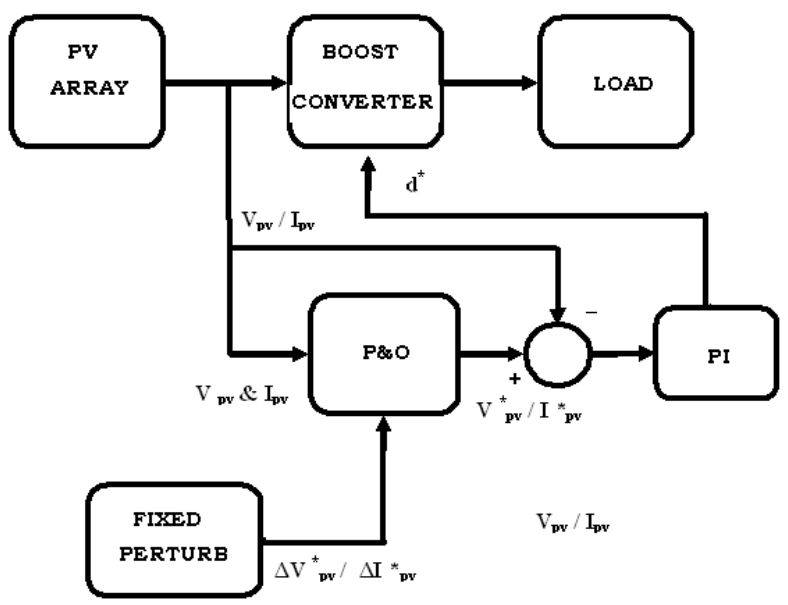

Fig.2 Block diagram of P\&O Algorithm

There are many different $\mathrm{P} \& \mathrm{O}$ methods available in the literature. In this paper we consider the classic, the optimized and the threepoints weight comparison algorithms. In the classic $\mathrm{P} \& \mathrm{O}$ technique $(\mathrm{P} \& \mathrm{O})$, the perturbations of the $\mathrm{PV}$ operating point have a fixed magnitude. In our analysis, the magnitude of perturbation is $0.37 \%$ of the PV array $V_{O V}$ (around $2 \mathrm{~V}$ ) . In the optimized $\mathrm{P} \& \mathrm{O}$ technique ( $\mathrm{P} \& \mathrm{Ob})$, an average of several samples of the array power is used to dynamically adjust the perturbation magnitude of the PV operating point.

In the three-point weight comparison method ( $\mathrm{P} \& \mathrm{Oc})$, the perturbation direction is decided by comparing the PV output power on three points of the $\mathrm{P}-\mathrm{V}$ curve. These three points are the current operation point $(\mathrm{A})$, a point $\mathrm{B}$ perturbed from point $\mathrm{A}$, and a point $\mathrm{C}$ doubly perturbed in the opposite direction from point $B$.

All three algorithms require two measurements: a measurement of the voltage $V_{P V}$ and a measurement of the current $I_{P V}$.

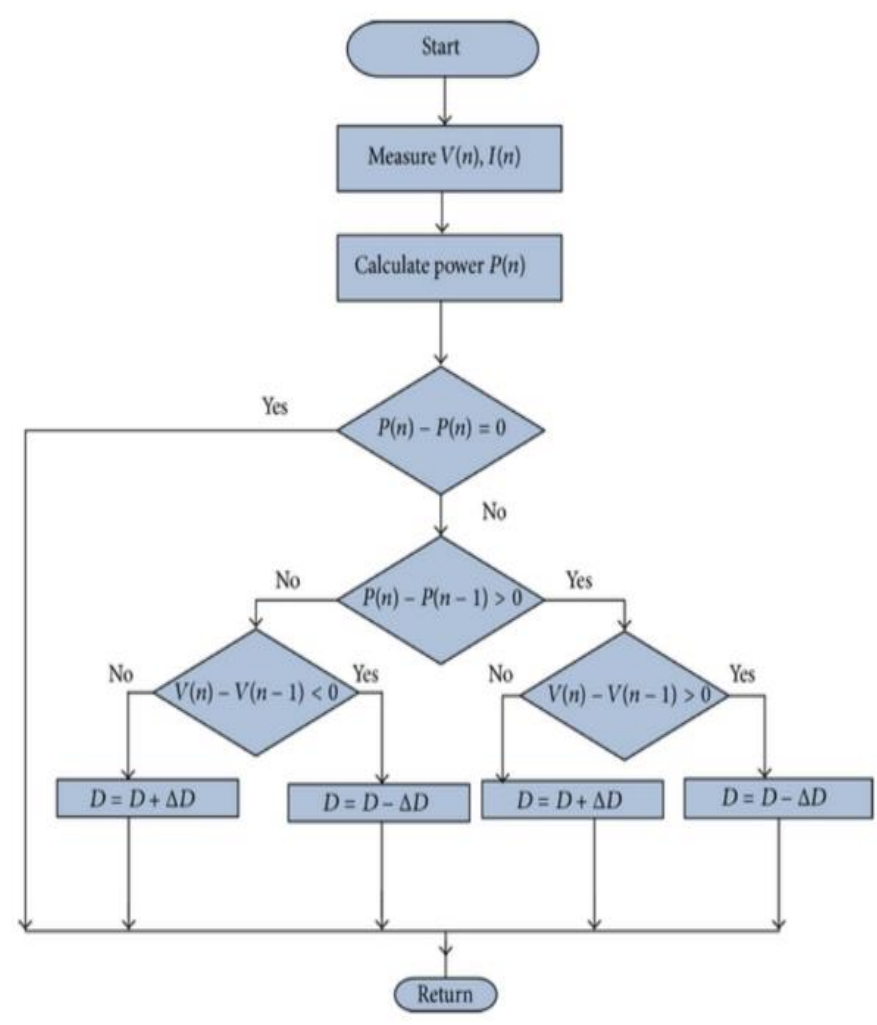

Fig.3 Flow chart of $\mathrm{P} \& \mathrm{O}$ algorithm

\section{MULTILEVEL CONVERTERS}

Multilevel-converter technology has experienced a fast growing attention in the last decade, and several topologies have been reported. This section is focused mainly on the most established and commercialized multilevel inverters, i.e., the three-level NPC, the four-level FC, and the CHB converter, that will be analyzed for seven levels, although it is also commercially available in 9,11 , and 13 levels.

\section{A. Neutral-Point Clamped}

1) Topology Description: In the early 1980s, a new pioneering converter topology was the three-level 
NPC voltage-source converter (3L NPC-VSC), also known as diode-clamped converter. Since all semiconductors are operated at a commutation voltage of half the dc-link voltage, the topology offered a simple solution to extend voltage and power ranges of the existing 2L-VSC technology, which were severely limited by the blocking voltages of power semiconductors withactive turn-on and turn-off capabilities.[4] Hence, the converter was of particular interest for MV applications (2.3-4.16 $\mathrm{kV}$ ). The 3L NPC-VSC was soon introduced to the market by leading manufacturers and gained more and more importance. NPC converters can be extended to generate more output-voltage levels However, these topologies have not found industrial acceptance to date and, therefore, will not be further discussed in this paper.

In a $2 \mathrm{~L} \mathrm{VSC}$, a series connection of two switches per switch position is required to enable an operation at the same $\mathrm{dc}$ and converter voltage like a $3 \mathrm{~L}$ NPC-VSC. The 3L NPC-VSC features two additional diodes per phase leg as compared to a $2 \mathrm{~L}$ VSC with a direct series connection of two devices per switch position. These so-called NPC diodes link the midpoint of the "indirect series connection" of the main switches to the neutral point of the converter.[5] This allows the connection of the phase output to the converter neutral point $N$ and enables the three-level characteristic of the topology. Table I shows the switch states of one phase leg.

Note that two pairs of switches of one leg receive inverted gate signals $S_{a k}$ and $S_{a k}(k=1,2)$ to enable a proper modulation and to avoid forbidden switch states.[6] The overall converter switching state can be defined by $S=\left(S_{a}, S_{b}, S_{c}\right)$, where, according to Table I, each phase switching state $S x(x=a, b, c)$ can be represented by a (+1) when generating $V_{\mathrm{de}} / 2$, a $(-1)$ when generating $-V_{\mathrm{dc}} / 2$, or a (0) when connected to the neutral point, hence generating zero-voltage level. Combining the states of all three phases, the 3L NPC-VSC features $n_{\mathrm{ss}}=L_{3}=33=27$ switch states, where $L$ is the number of voltage levels of $v_{x N}(x=a, b, c)$. The different switch states can be represented in the complex $\alpha-\beta$ frame, simply by calculating the space vector $\left(\mathbf{v}_{\mathrm{s}}\right)$ associated to each switching state[7]

$$
\begin{aligned}
\mathbf{v}_{\mathrm{s}} & =\frac{2}{3}\left[v_{a N}+a v_{b N}+a^{2} v_{c N}\right] \\
& =\frac{2}{3}\left[S_{a} \frac{V_{\mathrm{dc}}}{2}+a S_{b} \frac{V_{\mathrm{dc}}}{2}+a^{2} S_{c} \frac{V_{\mathrm{dc}}}{2}\right]
\end{aligned}
$$

where $a=e^{j 2 \pi / 3}$.Note that some switching states have redundant space-vector representations.
This redundancies can be used for neutral-point balance purposes.

2) Modulation Methods: There are different modulation schemes to generate the desired converter voltage. Commonly applied modulation methods in industry are the carrier-based sine-triangle modulation based on multiple-carrier arrangements in vertical shifts[8]. In addition, the space-vector modulation has been extended for the multilevel case and has been generalized via 3-D algorithms even for multiphase systems. Other methods, like SHE, have also been adapted for multilevel waveforms

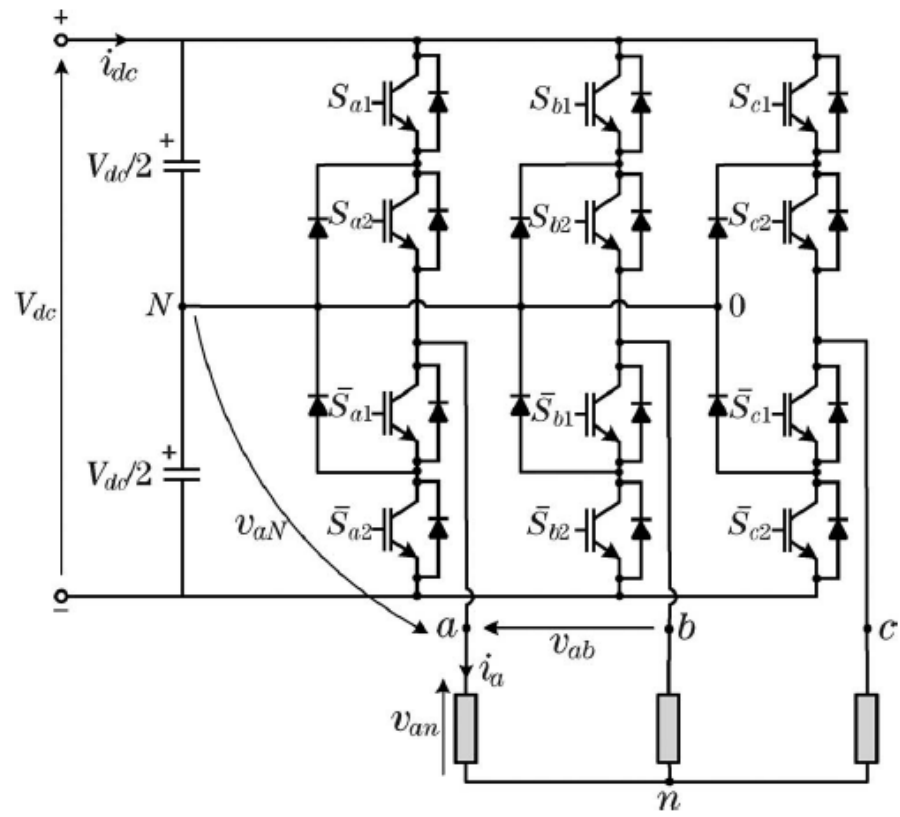

Fig.4 Circuit configuration of 3L NPC-VSC

\section{SINGLE PHASE INVERTER}

The single phase solar inverter is used for the purpose of conversion of DC power into $\mathrm{AC}$ power at required frequency and voltage output for applications. In this paper single phase PWM inverter for solar is discussed. Full bridge inverter and Half bridge inverter both are the types of single phase inverter. Full bridge inverter has four switches, the losing and opening of the switches in the right sequence coverts DC to AC. On the other hand the half bridge inverter has two switches. The switches gets $\mathrm{ON}$ and OFF alternately like complimenting each other. An output waveform of an ideal inverter should be sinusoidal but in the practical inverter the waveforms are non-sinusoidal and also contain some harmonics.

\section{CONCLUSION}

The simulation results showed clearly the performance of the dynamic voltage restorer (DVR) in compensation voltage sag and swell. The DVR handled both balanced and unbalanced situations without any difficulties and injected the appropriate voltage component to correct rapidly any disturbance in the supply voltage to keep the load voltage balanced and constant 
at the nominal value. Many paper worked on voltage improvement for sag or swell, but in the proposed model both are mitigated either required. To further boosts up the function of a DVR, we imply a few techniques. As the number of levels in a multilevel inverter raise, we can ensure harmonic free sinusoidal output, but the cost increases as the stage increases.

In this review paper, few MPPT techniques suitable and widely used for single phase inverter are discussed. To maintain the operating point of solar panel at optimum position and to get the point of maximum power MPPT is needed. From the brief study of the Different MPPT techniques, it is observed that the $\mathrm{P} \& \mathrm{O}$ technique is best suitable to implement the single phase inverter first solar applications. The results of P \& O MPPT and its simulation can be verified in the matlab simulink.

The historical Reviews of Different MPPT for solar inverter also shows that MPPT is needed for good and efficient working of the solar inverter. The conclusions made by the researchers are

A. Design of High Efficient MPPT Solar Inverter In this paper presented that a tracking system is more efficient than the existing stationary one. The output power is more in all the time domains in which the experiment was carried out. In the developed MPPT solar inverters the power consumed by the tracking system is found to be more, which can be reduced in the future works.[9]

B. Design and Development of Solar Panel Inverter with MPPT In this paper have given details regarding implementation of solar power tracing system. The interest of solar energy has become more important due to surging oil prices and environmental effect. In many remote or under develop areas, direct access to an electric grid is impossible and a photovoltaic inverter system would make life much simpler and has become convenient. The proposed system provides a variable indication of their relative angle to the sun by comparing with predefined measured readings. This project is main part of solar panels are used convert into light energy into electrical energy. The solar panel is also used in solar tracking this system to increase in panel efficiency in percent. The proposed design is having an low power consumption, low cost and high accuracy.[10]

C. A Review paper on various Types of MPPT Technique for PV system In this paper conclude that the growing industrialization of nations and hazardous environmental conditions has led us to increase our interest in renewable forms of energy such as solar energy. Photovoltaic power generation from solar energy is done through MPPT for efficient tracking. This review paper, describes a basic study of some of the MPPT techniques in nutshell. With this research paper the different MPPT techniques can be easily understood and can also be compared according to their implementation cost, tracking accuracy, PV array dependency, sensors etc.[11]

\section{REFERENCES}

[1] Anitha, "Quasi-Z-source Inverter based Dynamic Voltage Restorer," vol. 7, pp. 7-12.

[2] M. Farhadi-Kangarlu, "An interline dynamic voltage restorer using Neutral-Point-Clamped (NPC) multilevel converter," Adv. Electr. Electron. Eng., vol. 16, no. 1, pp. 46-56, 2018.

[3] T. Ambadi, R. Sagayaraj, and S. Hakeem, "Dynamic Voltage Restorer Using Multilevel Inverter Current Sensing For Photovoltaic," vol. 24, no. 9, pp. 67-71, 2017.

[4] G. Kumar and G. Venkateswarlu, "Compensation of Unbalanced Voltage Sag / Swell by Multilevel Inverter-Based Dynamic Voltage Restorer,' vol. 114, no. 7, pp. 11-20, 2017.

[5] A. Meena, S. Islam, S. Anand, Y. Sonawane, and S. Tungare, "Design and control of single-phase dynamic voltage restorer," Sādhanā, vol. 42, no. 8, pp. 1363-1375, 2017.

[6] H. N. Tran, P. Q. Dzung, N. A. Le, and T. D. Nguyen, "Dynamic voltage restorer-multilevel inverter based on predictive voltage controller," IEEE Int. Conf. Sustain. Energy Technol. ICSET, pp. 174-179, 2017.

[7] H. Iman-Eini and S. Galeshi, "Dynamic voltage restorer employing multilevel cascaded H-bridge inverter," IET Power Electron., vol. 9, no. 11, pp. 2196-2204, 2016.

[8]V. Srinivasan and M. Sujith, "Multilevel H-Bridge Dynamic Voltage Restorer with Harmonic Elimination,” pp. 7-18, 2016.

[9] K. A. Sunitha and G. Prem Kumar, "design of high efficient MPPT solar inverter", MATEC web of conference, 108, ICMAA 2017

[10] Prof. Swapnil R. Kurkute, Ms. Kakrale Priti Nivrutti, Ms. Kale Shraddha Sunil, Ms.Kudav Aboli Santosh, "PCB Quality Monitoring", International Journal of Modern Embedded System (IJMES), ISSN: 2320-9003(Online), Volume No.-5, Issue No.-1, February, 2017, Page No-13- 16

[11] Vaishali T. Tekade, Mrunali R. Kude, Bharat D. Deore, "design and development of solar panel inverter with MPPT”, international research journal of engineering and technology (IRJET), volume : 4 issue :4 /Apr 2017. 